\title{
Hemicellulosic biomass conversion by Moroccan hot spring Bacillus paralicheniformis CCMM B940 evidenced by glycoside hydrolase activities and whole genome sequencing
}

\author{
Soufiane Maski ${ }^{1,4} \cdot$ Serigne Inssa Ngom ${ }^{1,2}$ (D) Bahia Rached $^{1,3} \cdot$ Taha Chouati $^{1} \cdot$ Mohamed Benabdelkhalek $^{4}$. \\ Elmostafa El Fahime ${ }^{5}$ (D) Mohamed Amar $^{1,3} \cdot$ Christel Béra-Maillet $^{1,2}$ (D)
}

Received: 13 January 2021 / Accepted: 8 July 2021 / Published online: 22 July 2021

(c) The Author(s) 2021

\begin{abstract}
Thermophilic bacteria, especially from the genus Bacillus, constitute a huge potential source of novel enzymes that could be relevant for biotechnological applications. In this work, we described the cellulose and hemicellulose-related enzymatic activities of the hot spring Bacillus aerius CCMM B940 from the Moroccan Coordinated Collections of Microorganisms (CCMM), and revealed its potential for hemicellulosic biomass utilization. Indeed, B940 was able to degrade complex polysaccharides such as xylan and lichenan and exhibited activity towards carboxymethylcellulose. The strain was also able to grow on agriculture waste such as orange and apple peels as the sole carbon source. Whole-genome sequencing allowed the reclassification of CCMM B940 previously known as B. aerius into Bacillus paralicheniformis since the former species name has been rejected. The draft genome reported here is composed of 38 contigs resulting in a genome of 4,315,004 bp and an average $\mathrm{G}+\mathrm{C}$ content of $45.87 \%$, and is an important resource for illuminating the molecular mechanisms of carbohydrate metabolism. The annotated genomic sequences evidenced more than 52 genes encoding glycoside hydrolases and pectate lyases belonging to 27 different families of CAZymes that are involved in the degradation of plant cell wall carbohydrates. Genomic predictions in addition to in vitro experiments have revealed broad hydrolytic capabilities of the strain, thus reinforcing its relevance for biotechnology applications.
\end{abstract}

Keywords Bacillus paralicheniformis $\cdot$ Whole genome $\cdot$ Hemicellulose $\cdot$ Glycoside hydrolase $\cdot$ Lichenan $\cdot$ Xylan

Christel Béra-Maillet

christel.maillet@inrae.fr

Soufiane Maski

soufianemaski1@gmail.com

Serigne Inssa Ngom

serigneinssa.ngom@inrae.fr

Bahia Rached

rached@cnrst.ma

Taha Chouati

chouati@cnrst.ma

Elmostafa El Fahime

elfahime@cnrst.ma

Mohamed Amar

m.amar.cnrst@gmail.com
1 Laboratoire de Microbiologie et Biologie Moléculaire, Centre National pour la Recherche Scientifique et Technique, Rabat, Morocco

2 Université Paris-Saclay, INRAE, AgroParisTech, Micalis Institute, Jouy-en-Josas, France

3 Collections Coordonnées Marocaines de Microorganismes, Centre National pour la Recherche Scientifique et Technique, Rabat, Morocco

4 Département de Biologie, Faculté des Sciences, Université Mohammed V, Rabat, Morocco

5 Plateforme de biologie moléculaire et Génomique Fonctionnelle, Centre National pour la Recherche Scientifique et Technique, Rabat, Morocco 


\section{Genome research reports}

Lignocellulosic biomass, mainly composed of cellulose, hemicelluloses and lignin, is the most abundant complex biopolymer in the nature. It is of major interest for biotechnology as this feedstock is used for the production of renewable biofuels and other high-value chemicals, through an enzymatic saccharification process (Zhang et al. 2018). However, depolymerization of lignocellulose is challenging and it requires high-performance enzymes that act in synergy (Houfani et al. 2020). Therefore, enzymes produced by microorganisms, such as bacteria, are used for the deconstruction of the complex polysaccharides of cellulose and hemicelluloses which are tightly bound together in plant cell walls (Zeng et al. 2017).

Xylan is the main component of hemicelluloses and consists of a $\beta-1,4-D-x y l a n$ backbone with short side chains of $O$-acetyl, $\beta$-L-arabinofuranosyl, D- $\alpha$-glucuronic acid and phenolic acid (Biely et al. 2016). Other polysaccharides such as xyloglucan, lichenan and mannans are part of the hemicellulolytic fraction of plant cell walls. Xylanases, xyloglucanases, lichenases, and endoglucanases are necessary to completely degrade these polysaccharides into simple sugars to allow glycolytic fermentation to produce energy. These enzymes belong to one of the glycoside hydrolase $(\mathrm{GH})$ families, a subgroup of the carbohydrate-active enzymes (CAZymes) (Lombard et al. 2014) and very often associated with carbohydrate-binding modules (CBM) that facilitate adhesion of enzymes to cellulose or hemicelluloses.

Most microorganisms living in extreme environmental habitats such as hot springs have been considered attractive producers of lignocellulolytic enzymes for industrial bioconversion processes (Thapa et al. 2020). Morocco has more than 20 hot springs distributed in different regions (Cidu and Bahaj 2000; Bouchaou et al. 2017) which are suitable habitats for thermophilic microorganisms growing optimally between 55 and $80^{\circ} \mathrm{C}$. In addition, thermophilic bacteria are known for their ability to produce thermostable enzymes of biotechnological interest (Knapik et al. 2019). Previously, Aanniz et al. (2015) investigated the diversity of thermophilic bacteria in 4 different hot springs in Morocco, which enabled the isolation of 79 bacterial strains belonging to the genus Bacillus (www.ccmm.ma). Some of these strains were identified as Bacillus aerius. They grow optimally at $55^{\circ} \mathrm{C}$ and exhibit amylolytic, proteolytic or cellulolytic activity (Aanniz et al. 2015). However, strains belonging to B. aerius species should be reclassified as this species name has been rejected since 2015 (Dunlap 2015). For this reason, we chose the CCMM B940 strain as the representative of the B. aerius group isolated by Aanniz et al. (2015) from a hot spring for biological characterization of its potential hemicellulolytic and cellulolytic activities and whole-genome sequencing analysis.

B940 strain was grown twice on Luria-Bertani (LB) agar medium (BD Difco, Sparks, Maryland, USA) for $18 \mathrm{~h}$ at $37{ }^{\circ} \mathrm{C}$ under aerobic conditions. Individual colonies were then picked from LB plates and cultivated at $37^{\circ} \mathrm{C}$ for $18 \mathrm{~h}$ in LB agar medium supplemented with $0.5 \%$ Icelandic moss Lichenan (Megazyme, Wicklow, Irlande), beechwood Xylan (Megazyme, Wicklow, Irlande), or medium viscosity Carboxymethylcellulose (CMC, Sigma, MO, USA), respectively. A second bacterial strain (CCMM B945) from the same $B$. aerius group, known for inability to degrade lichenan and xylan (data not shown) was used as a negative control for degradation of hemicellulose and following the same experimental protocol as for CCMM B940. Both strains grew well on LB agar medium supplemented with purified fibres (Fig. 1A).

To reveal whether the strains were able to degrade the complex polysaccharides added into the medium, the plates were stained with $0.1 \%$ Congo red as previously described (Patrascu et al. 2017). Clear halos around the streaks indicated that B940 strain can degrade all three polysaccharides, and thus capable of producing the appropriate enzymes. As expected, lichenases and xylanases were only produced by the CCMM B940 strain (Fig. 1B). Strain CCMM B945 exhibited significant activity against $\mathrm{CMC}$, indicating production of endoglucanases, similar to the CCMM B940 strain.

The Congo red test demonstrated that live cells of the B940 strain exhibited lichenase and xylanase activities and also produced endoglucanases for glucan-polymer degradation. However, to evaluate biomass utilization potential of this strain for biotechnology applications, we searched for the presence of those enzymes in the rather easily accessible B940 strain supernatants. For this purpose, the strain was cultivated in the basal salt solution (BSS), a chemically defined medium modified from Parab et al. (2017), with a lower salt concentration $\left(\mathrm{NaCl} 6 \mathrm{~g} \mathrm{~L}^{-1}\right)$. The medium was supplemented with fruits peels (orange or apple) as the sole source of carbon and then sterilized 15 min at $121{ }^{\circ} \mathrm{C}$. Fruit peels are a rich source of cellulose, hemicellulose, lignin and pectin (Rivas et al. 2008; Joglekar et al. 2019). Orange peel is rich in structural polysaccharides, including cellulose (18-20\%), hemicellulose (14-16\%), pectin (20-22\%) and lignin (5-7\%) (de la Torre et al. 2019). Apple residues typically contain 7.2-43.6\% cellulose, $4.3-24.4 \%$ hemicellulose, $15.2-23.5 \%$ lignin and 3.5-14.32\% pectin (Dhillon et al. 2013). Both substrates were chosen because of their abundance as industrial waste around the world (de la Torre et al. 2019).

A single colony of CCMM B940 and CCMM B945 from $\mathrm{LB}$ agar medium was picked to inoculate $5 \mathrm{~mL}$ of LB Broth (Difco) and incubated overnight at $37^{\circ} \mathrm{C}$ (with 
A

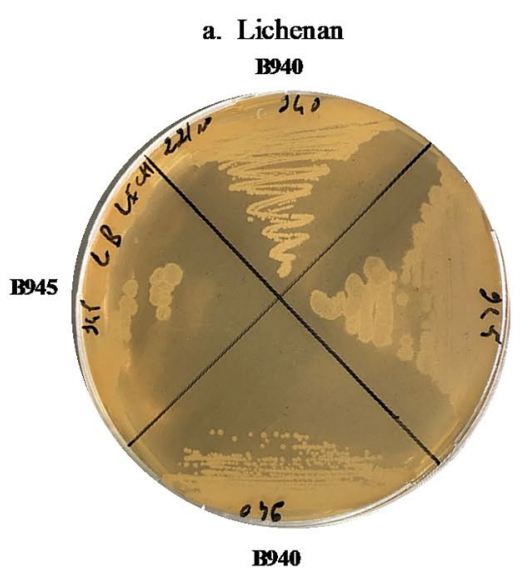

B

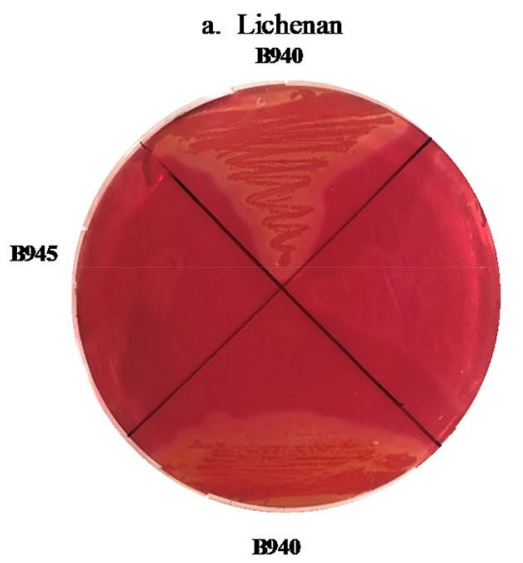

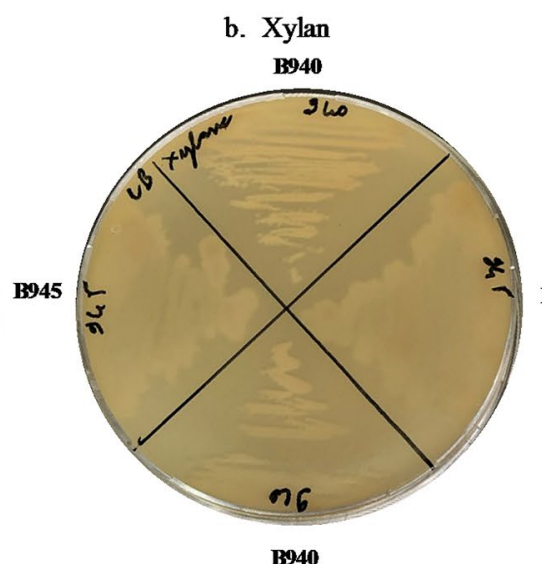

B940

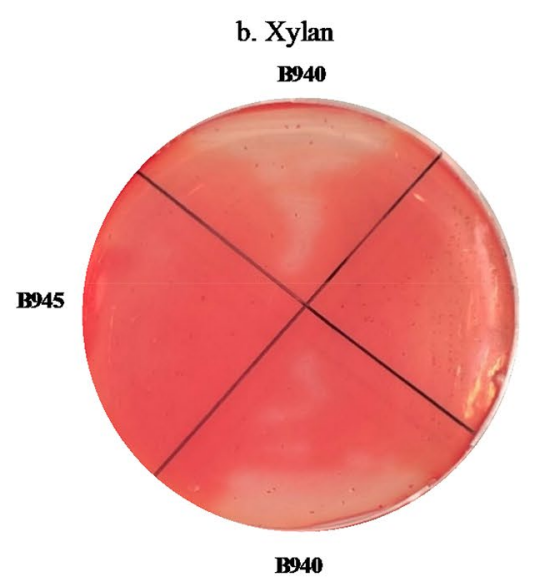

c. Carboxymethylcellulose

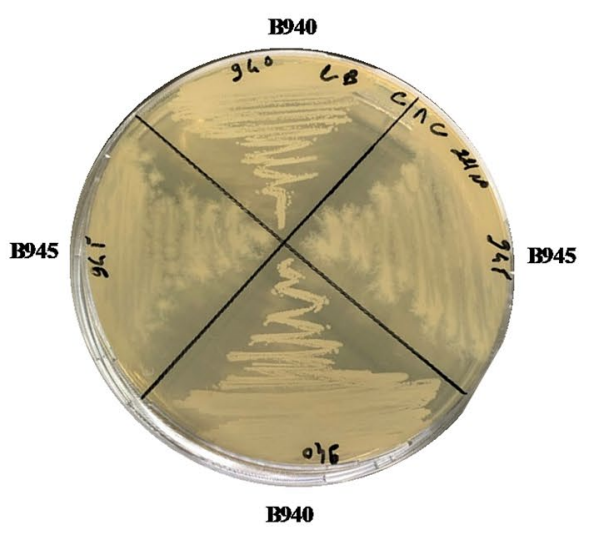

c. Carboxymethylcellulose

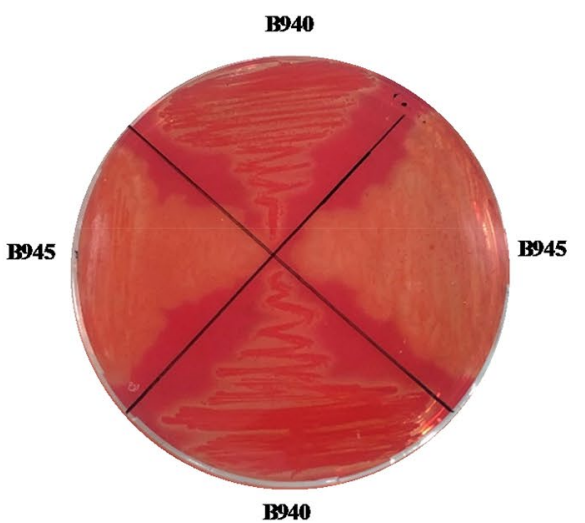

Fig. 1 Growth A and detection of lichenase (a), xylanase (b) and carboxymethylcellulase (c) activities B of Bacillus CCMM B940 and CCMM B945 strains cultivated in LB agar streak plates supplemented with $0.5 \%(\mathrm{w} / \mathrm{v})$ lichenan, xylan or carboxymethylcellulose
(CMC), respectively. Plates were incubated $18 \mathrm{~h}$ at $37{ }^{\circ} \mathrm{C}$. Congo red staining was performed as described in Patrascu et al. (2017). Clear halos around the streaks indicate the degradation of the corresponding polysaccharide. continuous stirring at $170 \mathrm{rpm}$ ), followed by second culture in $5 \mathrm{~mL}$ of BSS medium supplemented with $0.5 \%$ apple or orange peels and inoculated at $1 \%$. Before adding them in the medium, apple and orange peels were dried for $24 \mathrm{~h}$ at $60^{\circ} \mathrm{C}$ and crumbled finely using an electric grinder. After $48 \mathrm{~h}$ of incubation at $37^{\circ} \mathrm{C}$ with stirring (170 rpm), both strains grew well in the BSS supplemented with fruit peels representing agro-industrial wastes as shown in Figure S1. Additionally, this test confirmed the ability of CCMM B940 and CCMM B945 strains to break down fibres from the peels and use the degradation products.

Protein samples from B940 and B945 strains cultivated for $48 \mathrm{~h}$ at $37^{\circ} \mathrm{C}$ in $30 \mathrm{~mL}$ BSS medium supplemented with $0.5 \%$ orange and apple peels were prepared to detect and quantify hemicellulolytic and cellulolytic activities in the extracellular fluids. Briefly, cultures were centrifuged for $15 \mathrm{~min}$ at $5000 \times \mathrm{g}$ and $4{ }^{\circ} \mathrm{C}$, supernatants were filtered through a $0.22 \mu \mathrm{m}$ Millipore filter, and then concentrated 25-fold in a Spin-X UF10K concentrator following the supplier's protocol (Corning B.V., Amsterdam, The Netherlands).

Agar-well plate enzymatic assays were performed to detect xylanase, lichenase and endoglucanase activities using concentrated extracellular proteins. Concentrated extracellular proteins from CCMM B940 and control strain CCMM B945 were prepared in the same way. The samples were loaded $(60 \mu \mathrm{L} /$ well $)$ in Petri dishes containing BSS medium supplemented with either $0.1 \%$ chromogenic AZCL-Xylan (Megazyme, Wicklow, Ireland), 0.5\% non-chromogenic CMC (Sigma-Aldrich, MO, USA) or lichenan (Megazyme) polysaccharides. The plates were incubated overnight at $37{ }^{\circ} \mathrm{C}$ and those with non-chromogenic polysaccharide were stained with Congo red as described above. Clear and blue halos around the wells indicated that the CCMM B940 cultivated with apple peels was able to produce lichenase (Fig. 2A), endoglucanase (Fig. 2C, although weakly in the tested conditions), and xylanase (Fig. 2B). The same results were obtained with orange peels (not shown). 


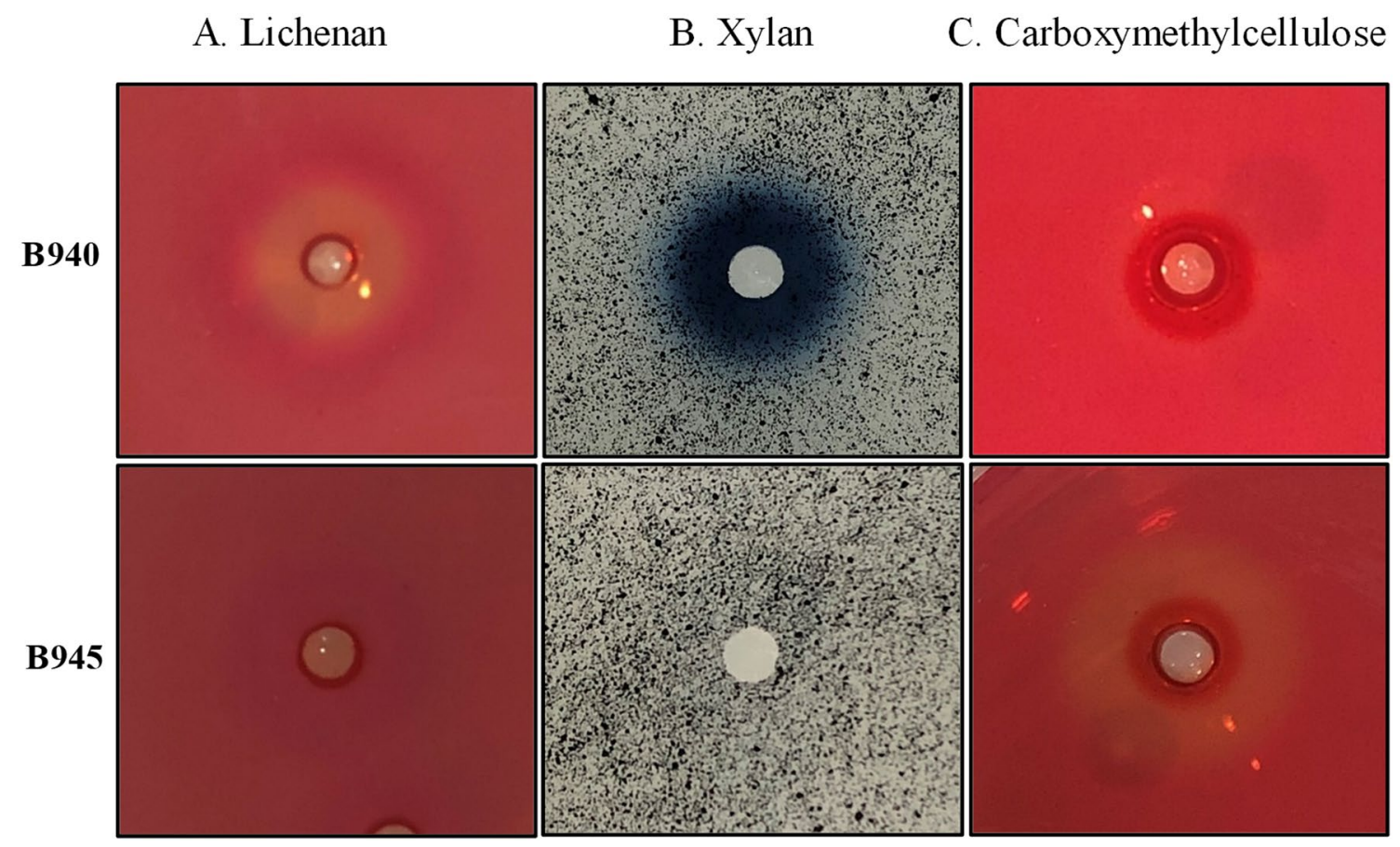

Fig. 2 Detection of lichenase A, xylanase $\mathbf{B}$ and carboxymethylcellulase C activities of Bacillus CCMM B940 and B945 strains, using agar-well plate assays with concentrated extracellular proteins of BSS cultures with $0.5 \%$ apple. Agar plate BSS medium was supplemented with $0.5 \%$ (w/v) lichenan, carboxymethylcellulose (CMC), or $0.1 \%$ AZCL beechwood xylans. Plates were incubated overnight at $37^{\circ} \mathrm{C}$. Clear and blue halos around the wells indicate a positive sample for the corresponding glycoside hydrolase activity
The CCMM B940 strain is able to grow at $55^{\circ} \mathrm{C}$ in Tryptic Soy broth (Aanniz et al. 2015) and we also observed that the strain is capable of growing in BSS medium supplemented with lichenan and xylan at the same temperature (data not shown), thus reinforcing the interest of its characteristics for industrial applications requiring thermostable enzymes.

In contrast to CCMM B940 strain results, the control strain CCMM B945 was not able to produce xylanase or lichenase when cultivated in the presence of apple or orange peels (Fig. 2).

Moreover, extracellular hemicellulolytic activities of the strain CCMM B940 were quantified using the dinitrosalicylic acid (DNS) spectrophotometric method for reducing sugars as described by Miller (1959). Protein concentration was determined by the Bradford protocol (Bradford 1976) with bovine serum albumin (BSA) as the standard. The amount of protein samples and the incubation time were chosen to provide assay conditions in which the measured activity was proportional to these two parameters. The enzymatic assays were all carried out at $55^{\circ} \mathrm{C}$ to quantify the activities under conditions close to those of industrial processes using thermostable enzymes. Reducing sugars that were released after enzyme-substrate incubations were quantified in triplicates using glucose or xylose as a standard. One international unit (IU) was defined as the amount of enzyme, which produced $1 \mu \mathrm{mol}$ of reducing sugars in $1 \mathrm{~min}$. The xylanase and lichenase activities of the extracellular proteins from

Table 1 Lichenase and xylanase specific activities of extracellular proteins from Bacillus CCMM B940 and CCMM B945 cultivated in BSS medium supplemented with $0.5 \%$ apple and orange peels

\begin{tabular}{llllll}
\hline Strains & Apple & & & Orange \\
\cline { 2 - 3 } & CCMM B940 & CCMM B945 & & CCMM B940 & CCMM B945 \\
\hline Lichenase activity (IU/mg) & $4.06 \pm 1.1$ & nd & nd & $1.6 \pm 0.2$ & nd \\
Xylanase activity (IU/mg) & $2.39 \pm 0.29$ & nd & $0.98 \pm 0.2$ & n \\
\hline
\end{tabular}

Specific activities are given as $\mu \mathrm{mol}$ of glucose (incubation with lichenan) or xylose (incubation with xylans) equivalent produced per min and per $\mathrm{mg}$ of protein. Each value is the mean of three different assays $( \pm \mathrm{SD})$

nd not detectable 
BSS cultures with $0.5 \%$ apple and orange peels are listed in Table 1. Strain CCMM B945 was again used as a control. No reducing sugars was detectable for strain CCMM B945 proteins incubated with xylan or lichenan. The lichenase activity of CCMM B940 was approximately two times higher than the xylanase activity in the cultures with natural peels. Both activities were higher in apple peel cultures than in orange peels, suggesting that the produced enzymes were either more numerous or more active in metabolizing carbohydrates in apple peels. This could be due to the nature of fibres present in the peel (sugar composition and types of glycosidic bonds) and/or to differential induction of glycoside hydrolases encoding gene expression. Strain CCMM B940 exhibited xylanase activities approximately twofold and over tenfold higher in apple peel cultures than thermophilic strains B. licheniformis 2D55 (Kazeem et al. 2017) and Bacillus sp. 275 (Gong et al. 2017), respectively.

To further investigate the putative functions of the CCMM B940 strain and to achieve its reclassification within the genus Bacillus, we sequenced and examined the whole genome of this strain. Thus, genomic DNA was extracted with Wizard ${ }^{\circledR}$ Genomic DNA Purification Kit (Promega, Charbonnières-les-Bains, France). The concentration and quality were determined using Nanodrop and Qubit spectrophotometers. Genomic DNA was sequenced at Eurofins Genomics (Cologne, Germany) using Illumina HiSeq technology. The library was prepared with $2 \times 150$-bp paired-end read length, including DNA fragmentation, adapter ligation, amplification, and size selection. All the steps were performed according to Eurofins Genomics protocols, producing 7,612,190 reads.

The raw reads were then trimmed using Trimmomatic v0.39 (Bolger et al. 2014) with the following parameters: SLIDINGWINDOW:4:20; ILLUMINACLIP: TruSeq3-PE. fa:2:30:20:2: LEADING:3, TRAILING:3 and MINLEN:60. We verified the presence/absence of phix sequences using bowtie2 (Langmead and Salzberg 2012) with the following parameters: -trim-to 80 -end-to-end -no-unal -no-sq -nohead $-\mathrm{p} 12$. Processed reads were then assembled using the SPAdes de novo assembler v3.13.1 (Bankevich et al. 2012) testing assemblies with k-mer values: $21,33,55,77$ using the parameter: -careful. Depending on the size of insert,

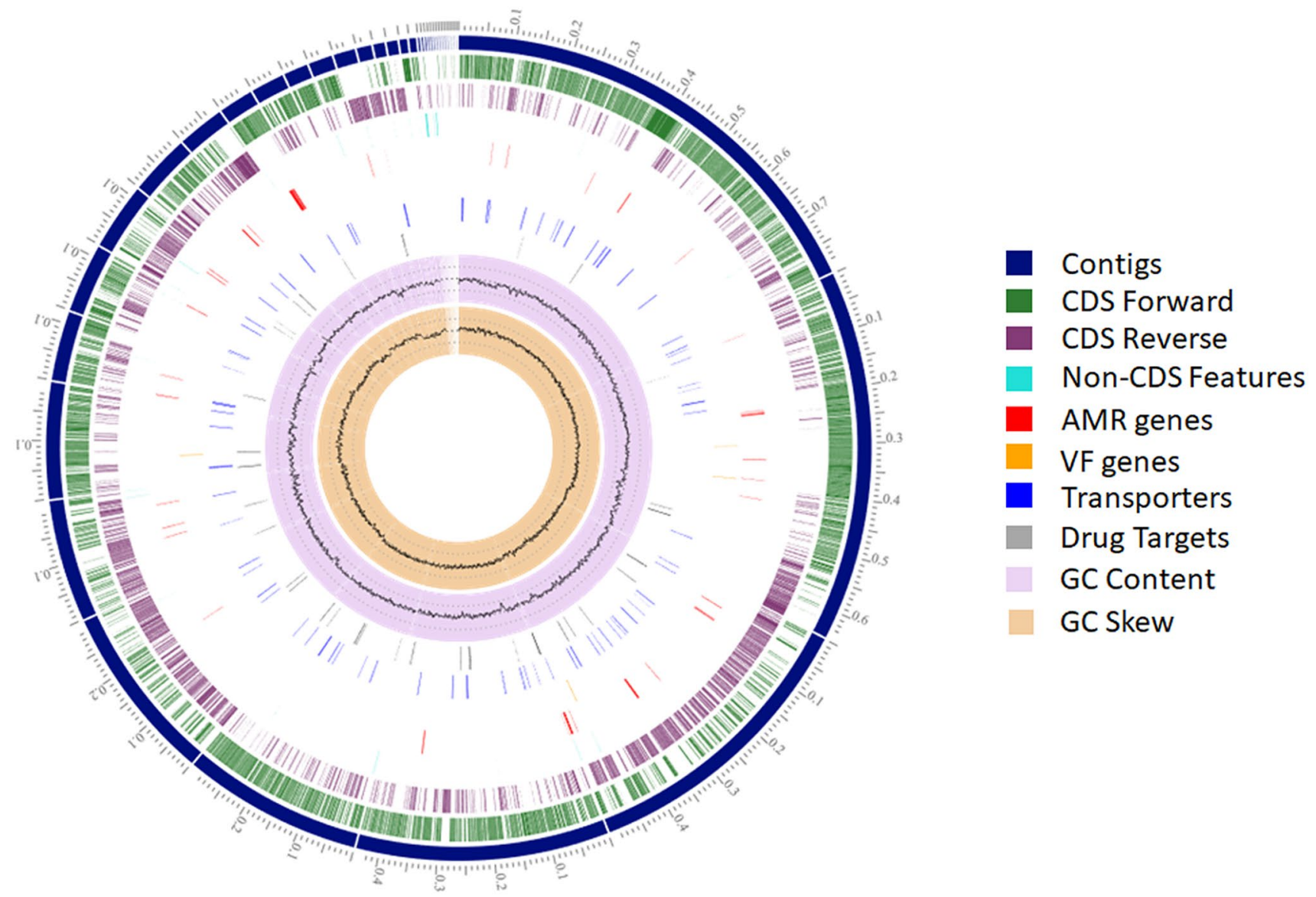

Fig. 3 Circular representation of the B. paralicheniformis CCMM B940 chromosome using PATRIC based on 34 assembled scaffolds. From outer to inner ring-contigs (scale-x1Mbp), CDS on the for- ward strand, CDS on the reverse strand, RNA genes, homologous CDS to known antimicrobial resistance (AMR) genes, CDS with homology to known virulence factors (VF), GC content and GC skew 
scaffolds smaller than $350 \mathrm{bp}$ were filtered out. Assembly quality was assessed using in-house script and QUAST v5.0.0 (Gurevich et al. 2013). We estimated genome completeness at $99.59 \%$ and checked that no contamination was detected using CheckM v1.1.3 (Parks et al. 2015).

After eliminating low coverage and small contigs $(<350 \mathrm{bp})$, we obtained a total of 38 contigs and 34 scaffolds resulting in a genome of 4,315,004 bp (NCBI accession number JADRJL000000000) and an average $\mathrm{G}+\mathrm{C}$ content of $45.87 \%$ which is close to other genomes from the Bacillus subtilis group (Rey et al. 2004; Du et al. 2019).The $N 50$ of the draft genome is $440,121 \mathrm{bp}$, with an average of 126,912 bp and a notable four gap region (Fig. 3). Species identity was confirmed by comparing the genome reference sequences of B. licheniformis and Bacillus paralicheniformis available in the NCBI database (https://www.ncbi.nlm.nih. gov) using the BLAST service deployed on local servers with the genome obtained sequences and fastANI (Jain et al. 2018). The draft genome was most closely related to B. paralicheniformis Bac84 (accession number ASM299392v1) living in sea environment (Othoum et al. 2019) with an ANI value of $98.94 \%$, and shared only $94.36 \%$ identity with $B$. licheniformis DSM 13 ${ }^{\mathrm{T}}$ (NC_006270.3). B. aerius CCMM B940 was, therefore, reclassified as B. paralicheniformis CCMM B940, placing it in the B. subtilis group; a group known for its wide array of uses in biotechnology mainly

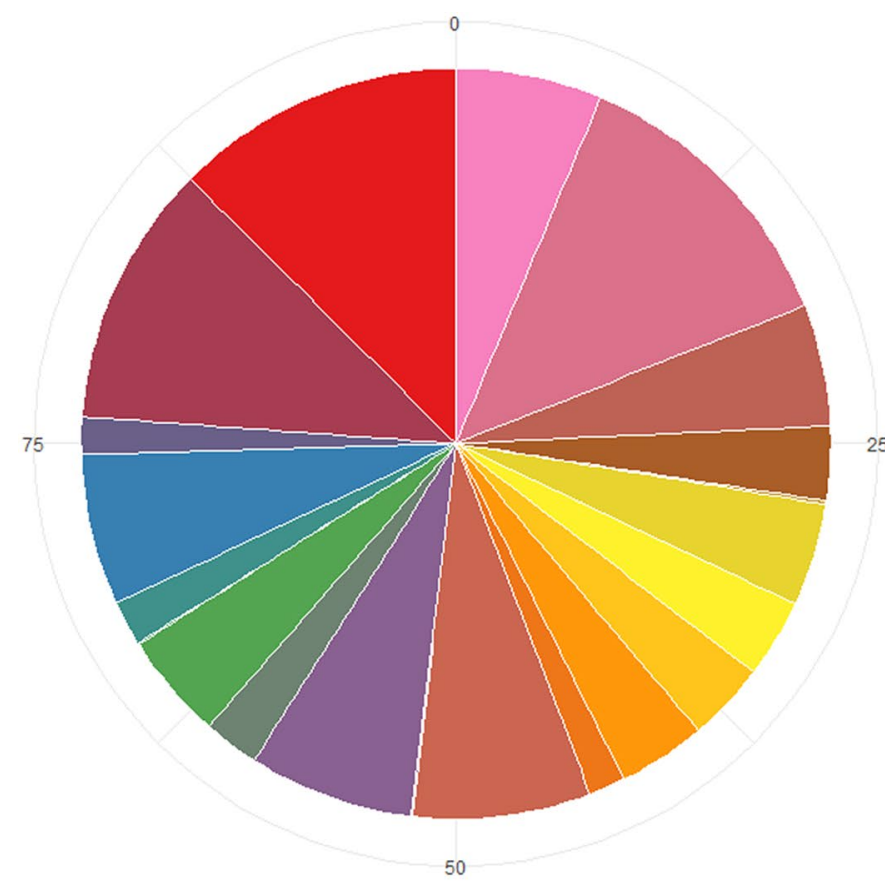

through species like $B$. subtilis and B. licheniformis (Fan et al. 2017). Taxonomic identity of the CCMM B940 strain was also confirmed using the GTDB-Tk tool for genome classification (Chaumeil et al. 2020) with $98.95 \%$ identity to the $B$. paralicheniformis $\mathrm{KJ}-16$ genome (accession number ASM104248v2). The genome was then annotated using the default parameters of Prokka 1.14 (Seemann 2014) showing 4259 protein-coding genes, 51 tRNAs and 4 complete rRNAs.

We further used eggNOG-mapper v2.0.1 (Huerta-Cepas et al. 2017) to assign proteins sequences into functional categories. More than $76 \%$ of the predicted proteins were attributed to functional subsystems. Proportions of genes with known functions (3047 CDS) were assigned to each category as presented in Fig. 4. Interestingly, a high proportion of CCMM B940 genes was assigned to the carbohydrate transport and metabolism (11.3\%) as well as aminoacid transport and metabolism (12.5\%) proteins. In a study conducted on Bacillus velenzis, Bacillus safensis and Bacillus altitudinis genomes, only $6.1 \%$ of the predicted proteins were assigned to carbohydrate transport and metabolism (Datta et al. 2020), while in Bacillus amyloliquefaciens and Bacillus siamensis, it represents a maximum of $8 \%$ in the pan and the core genomes (Chun et al. 2019). B. paralicheniformis has not been thoroughly studied for carbohydrate metabolism yet, but is phylogenetically very close to the $B$.

Percentage

Amino acid transport and metabolism (12,5\%)

Carbohydrate transport and metabolism (11,3\%)

Cell cycle control, cell division, chromosome partitioning $(1,6 \%)$

Cell wall/membrane/envelope biogenesis $(6,5 \%)$

Cellmotility $(1,9 \%)$

Chromatin structure and dynamics $(0,03 \%)$

Coenzyme transport and metabolism $(4,6 \%)$

Defense mechanisms (2,4\%)

Energy production and conversion $(7,2 \%)$

Extracellula rstructures $(0,03 \%)$

Inorganic ion transport and metabolism $(7,7 \%)$

Intracellular trafficking, secretion, and vesicular transport (1,6\%)

Lipid transport and metabolism (3,8\%)

Nucleotide transport and metabolism $(3,4 \%)$

Posttranslational modification, protein turnover, chaperones $(3,4 \%)$

Replication, recombination and repair $(4,4 \%)$

RNA processing and modification $(0,1 \%)$

Secondary metabolites biosynthesis, transport and catabolism $(3,2 \%)$

Signal transduction mechanisms $(5,3 \%)$

Transcription (12,7\%)

Translation, ribosomal structure and biogenesis $(6,3 \%)$

Fig. 4 Distribution of biological functions of B. paralicheniformis CCMM B940 based on eggNOG analysis. Colors show different gene features categories and their proportions. Percentages of genes with known functions are given within parentheses 
Table 2 Annotated genes encoding lignocellulose-degrading enzymes in B. paralicheniformis CCMM B940

\begin{tabular}{|c|c|c|c|c|c|c|c|c|}
\hline \multirow[t]{2}{*}{ Enzymes } & \multirow{2}{*}{$\begin{array}{l}\text { Accession } \\
\text { number }\end{array}$} & \multirow[t]{2}{*}{ Activity } & \multirow{2}{*}{$\begin{array}{l}\text { CAZyme } \\
\text { family }\end{array}$} & \multicolumn{2}{|c|}{ Reference genes } & \multirow[t]{2}{*}{ Identity (\%) } & \multirow{2}{*}{$\begin{array}{l}\text { Subject } \\
\text { sequence } \\
\text { length (bp) }\end{array}$} & \multirow{2}{*}{$\begin{array}{l}\text { Alignment } \\
\text { length (bp) }\end{array}$} \\
\hline & & & & $\begin{array}{l}\text { Accession } \\
\text { number }\end{array}$ & Species & & & \\
\hline \multirow[t]{14}{*}{$\begin{array}{l}\text { Hemicellu- } \\
\text { lose related }\end{array}$} & $\begin{array}{l}\text { EOOON- } \\
\text { OAK_01749 }\end{array}$ & $\begin{array}{l}\text { Aryl-phospho-beta- } \\
\text { D-glucosidase BglC }\end{array}$ & GH1 & ARA87766.1 & $\begin{array}{l}\text { Bacillus par- } \\
\text { alicheni- } \\
\text { formis } \\
\text { MDJK30 }\end{array}$ & 99.78 & 472 & 472 \\
\hline & $\begin{array}{l}\text { EOOON- } \\
\text { OAK_03335 }\end{array}$ & $\begin{array}{l}\text { Aryl-phospho-beta- } \\
\text { D-glucosidase BglH }\end{array}$ & GH1 & AGN35231.1 & $\begin{array}{l}\text { Bacillus par- } \\
\text { alicheni- } \\
\text { formis } \\
\text { ATCC } \\
9945 \mathrm{a}\end{array}$ & 100 & 100 & 100 \\
\hline & $\begin{array}{l}\text { EOOON- } \\
\text { OAK_03002 }\end{array}$ & $\begin{array}{l}\text { Aryl-phospho-beta- } \\
\text { D-glucosidase BglC }\end{array}$ & GH1 & AJO16530.1 & $\begin{array}{l}\text { Bacillus par- } \\
\text { alicheni- } \\
\text { formis } \\
\text { BL-09 }\end{array}$ & 100 & 491 & 478 \\
\hline & $\begin{array}{l}\text { EOOON- } \\
\text { OAK_01773 }\end{array}$ & $\begin{array}{l}\text { Aryl-phospho-beta- } \\
\text { D-glucosidase BglH }\end{array}$ & $\mathrm{GH} 1$ & QEO05069.1 & $\begin{array}{l}\text { Bacillus par- } \\
\text { alicheni- } \\
\text { formis } \\
\text { A4-3 }\end{array}$ & 99.57 & 469 & 469 \\
\hline & $\begin{array}{l}\text { EOOON- } \\
\text { OAK_03715 }\end{array}$ & $\begin{array}{l}\text { Endo-1,4-beta-xyla- } \\
\text { nase A }\end{array}$ & GH11 & QEO05734.1 & $\begin{array}{l}\text { Bacillus par- } \\
\text { alicheni- } \\
\text { formis } \\
\text { A4-3 }\end{array}$ & 100 & 213 & 213 \\
\hline & $\begin{array}{l}\text { EOOON- } \\
\text { OAK_02553 }\end{array}$ & Beta-glucanase & GH16 & ARA86799.1 & $\begin{array}{l}\text { Bacillus par- } \\
\text { alicheni- } \\
\text { formis } \\
\text { MDJK30 }\end{array}$ & 99.59 & 243 & 243 \\
\hline & $\begin{array}{l}\text { EOOON- } \\
\text { OAK_03322 }\end{array}$ & $\begin{array}{l}\text { Mannan endo- } \\
\text { 1,4-beta-mannosi- } \\
\text { dase }\end{array}$ & GH26 & QFY39913.1 & $\begin{array}{l}\text { Bacillus par- } \\
\text { alicheni- } \\
\text { formis FA6 }\end{array}$ & 98.89 & 360 & 360 \\
\hline & $\begin{array}{l}\text { EOOON- } \\
\text { OAK_03205 }\end{array}$ & Beta-hexosaminidase & GH3 & QEO05378.1 & $\begin{array}{l}\text { Bacillus par- } \\
\text { alicheni- } \\
\text { formis } \\
\text { A4-3 }\end{array}$ & 99.69 & 644 & 643 \\
\hline & $\begin{array}{l}\text { EOOON- } \\
\text { OAK_02186 }\end{array}$ & $\begin{array}{l}\text { Glucuronoxylanase } \\
\text { XynC }\end{array}$ & GH30 & AJO20016.1 & $\begin{array}{l}\text { Bacillus par- } \\
\text { alicheni- } \\
\text { formis } \\
\text { BL-09 }\end{array}$ & 100 & 420 & 420 \\
\hline & $\begin{array}{l}\text { EOOON- } \\
\text { OAK_01418 }\end{array}$ & $\begin{array}{l}\text { Oligosaccharide } \\
\text { 4-alpha-D-glucosyl- } \\
\text { transferase }\end{array}$ & GH31 & QFY38704.1 & $\begin{array}{l}\text { Bacillus par- } \\
\text { alicheni- } \\
\text { formis FA6 }\end{array}$ & 99.75 & 802 & 802 \\
\hline & $\begin{array}{l}\text { EOOON- } \\
\text { OAK_02225 }\end{array}$ & Alpha-xylosidase & GH31 & AJO19971.1 & $\begin{array}{l}\text { Bacillus par- } \\
\text { alicheni- } \\
\text { formis } \\
\text { BL-09 }\end{array}$ & 99.61 & 769 & 769 \\
\hline & $\begin{array}{l}\text { EOOON- } \\
\text { OAK_02112 }\end{array}$ & $\begin{array}{l}\text { Levanbiose-producing } \\
\text { levanase }\end{array}$ & GH32 & ARA87316.1 & $\begin{array}{l}\text { Bacillus par- } \\
\text { alicheni- } \\
\text { formis } \\
\text { MDJK30 }\end{array}$ & 99.8 & 515 & 495 \\
\hline & $\begin{array}{l}\text { EOOON- } \\
\text { OAK_01584 }\end{array}$ & $\begin{array}{l}\text { Sucrose-6-phosphate } \\
\text { hydrolase }\end{array}$ & GH32 & AJO20434.1 & $\begin{array}{l}\text { Bacillus par- } \\
\text { alicheni- } \\
\text { formis } \\
\text { BL-09 }\end{array}$ & 99.37 & 478 & 478 \\
\hline & $\begin{array}{l}\text { EOOON- } \\
\text { OAK_01729 }\end{array}$ & $\begin{array}{l}\text { Sucrose-6-phosphate } \\
\text { hydrolase }\end{array}$ & GH32 & AJO20595.1 & $\begin{array}{l}\text { Bacillus par- } \\
\text { alicheni- } \\
\text { formis } \\
\text { BL-09 }\end{array}$ & 98.98 & 492 & 492 \\
\hline
\end{tabular}


Table 2 (continued)

\begin{tabular}{|c|c|c|c|c|c|c|c|c|}
\hline \multirow[t]{2}{*}{ Enzymes } & \multirow{2}{*}{$\begin{array}{l}\text { Accession } \\
\text { number }\end{array}$} & \multirow[t]{2}{*}{ Activity } & \multirow{2}{*}{$\begin{array}{l}\text { CAZyme } \\
\text { family }\end{array}$} & \multicolumn{2}{|c|}{ Reference genes } & \multirow[t]{2}{*}{ Identity (\%) } & \multirow{2}{*}{$\begin{array}{l}\text { Subject } \\
\text { sequence } \\
\text { length (bp) }\end{array}$} & \multirow{2}{*}{$\begin{array}{l}\text { Alignment } \\
\text { length (bp) }\end{array}$} \\
\hline & & & & $\begin{array}{l}\text { Accession } \\
\text { number }\end{array}$ & Species & & & \\
\hline & $\begin{array}{l}\text { EOOON- } \\
\text { OAK_00085 }\end{array}$ & Levanase & GH32CBM66 & QFY38018.1 & $\begin{array}{l}\text { Bacillus par- } \\
\text { alicheni- } \\
\text { formis FA6 }\end{array}$ & 100 & 677 & 677 \\
\hline & $\begin{array}{l}\text { EOOON- } \\
\text { OAK_02224 }\end{array}$ & Hypothetical protein & GH3CBM6 & AJO19972.1 & $\begin{array}{l}\text { Bacillus par- } \\
\text { alicheni- } \\
\text { formis } \\
\text { BL-09 }\end{array}$ & 100 & 980 & 980 \\
\hline & $\begin{array}{l}\text { EOOON- } \\
\text { OAK_03904 }\end{array}$ & $\begin{array}{l}\text { Beta-galactosidase } \\
\text { BglY }\end{array}$ & GH42 & ARA84401.1 & $\begin{array}{l}\text { Bacillus par- } \\
\text { alicheni- } \\
\text { formis } \\
\text { MDJK30 }\end{array}$ & 99.42 & 690 & 690 \\
\hline & $\begin{array}{l}\text { EOOON- } \\
\text { OAK_04173 }\end{array}$ & $\begin{array}{l}\text { Beta-galactosidase } \\
\text { YesZ }\end{array}$ & GH42 & QFY39293.1 & $\begin{array}{l}\text { Bacillus par- } \\
\text { alicheni- } \\
\text { formis FA6 }\end{array}$ & 100 & 665 & 665 \\
\hline & $\begin{array}{l}\text { EOOON- } \\
\text { OAK_01837 }\end{array}$ & $\begin{array}{l}\text { Beta-galactosidase } \\
\text { GanA }\end{array}$ & GH42 & QFY40673.1 & $\begin{array}{l}\text { Bacillus par- } \\
\text { alicheni- } \\
\text { formis FA6 }\end{array}$ & 99.56 & 684 & 684 \\
\hline & $\begin{array}{l}\text { EOOON- } \\
\text { OAK_03858 }\end{array}$ & Beta-xylosidase & GH43 & ARA84797.1 & $\begin{array}{l}\text { Bacillus par- } \\
\text { alicheni- } \\
\text { formis } \\
\text { MDJK30 }\end{array}$ & 99.62 & 532 & 532 \\
\hline & $\begin{array}{l}\text { EOOON- } \\
\text { OAK_03859 }\end{array}$ & $\begin{array}{l}\text { Non-reducing end } \\
\text { alpha-L-arabinofura- } \\
\text { nosidase }\end{array}$ & GH43 & ARA84798.1 & $\begin{array}{l}\text { Bacillus par- } \\
\text { alicheni- } \\
\text { formis } \\
\text { MDJK30 }\end{array}$ & 99.03 & 515 & 515 \\
\hline & $\begin{array}{l}\text { EOOON- } \\
\text { OAK_03489 }\end{array}$ & $\begin{array}{l}\text { Extracellular endo- } \\
\text { alpha-(1->5)-L-ara- } \\
\text { binanase } 1\end{array}$ & GH43 & ARA85201.1 & $\begin{array}{l}\text { Bacillus par- } \\
\text { alicheni- } \\
\text { formis } \\
\text { MDJK30 }\end{array}$ & 100 & 316 & 316 \\
\hline & $\begin{array}{l}\text { EOOON- } \\
\text { OAK_00089 }\end{array}$ & Beta-xylosidase & GH43 & ARA86580.1 & $\begin{array}{l}\text { Bacillus par- } \\
\text { alicheni- } \\
\text { formis } \\
\text { MDJK30 }\end{array}$ & 100 & 533 & 533 \\
\hline & $\begin{array}{l}\text { EOOON- } \\
\text { OAK_01777 }\end{array}$ & $\begin{array}{l}\text { Extracellular endo- } \\
\text { alpha-(1->5)-L-ara- } \\
\text { binanase } 2\end{array}$ & GH43 & ARA88110.1 & $\begin{array}{l}\text { Bacillus par- } \\
\text { alicheni- } \\
\text { formis } \\
\text { MDJK30 }\end{array}$ & 99.79 & 469 & 469 \\
\hline & $\begin{array}{l}\text { EOOON- } \\
\text { OAK_02586 }\end{array}$ & $\begin{array}{l}\text { Extracellular endo- } \\
\text { alpha-(1->5)-L-ara- } \\
\text { binanase } 1\end{array}$ & GH43 & QFY37786.1 & $\begin{array}{l}\text { Bacillus par- } \\
\text { alicheni- } \\
\text { formis FA6 }\end{array}$ & 99.69 & 320 & 320 \\
\hline & $\begin{array}{l}\text { EOOON- } \\
\text { OAK_02185 }\end{array}$ & $\begin{array}{l}\text { Arabinoxylan arabino- } \\
\text { furanohydrolase }\end{array}$ & GH43CBM6 & QFY37223.1 & $\begin{array}{l}\text { Bacillus par- } \\
\text { alicheni- } \\
\text { formis FA6 }\end{array}$ & 100 & 515 & 515 \\
\hline & $\begin{array}{l}\text { EOOON- } \\
\text { OAK_01157 }\end{array}$ & hypothetical protein & GH5 & ARA85656.1 & $\begin{array}{l}\text { Bacillus par- } \\
\text { alicheni- } \\
\text { formis } \\
\text { MDJK30 }\end{array}$ & 99.82 & 560 & 560 \\
\hline & $\begin{array}{l}\text { EOOON- } \\
\text { OAK_02594 }\end{array}$ & $\begin{array}{l}\text { Intracellular exo- } \\
\text { alpha-(1->5)-L-ara- } \\
\text { binofuranosidase }\end{array}$ & GH51 & ARA86758.1 & $\begin{array}{l}\text { Bacillus par- } \\
\text { alicheni- } \\
\text { formis } \\
\text { MDJK30 }\end{array}$ & 99.80 & 502 & 502 \\
\hline & $\begin{array}{l}\text { EOOON- } \\
\text { OAK_01836 }\end{array}$ & $\begin{array}{l}\text { Arabinogalactan } \\
\text { endo-beta-1,4-ga- } \\
\text { lactanase }\end{array}$ & GH53 & AGN38579.1 & $\begin{array}{l}\text { Bacillus par- } \\
\text { alicheni- } \\
\text { formis } \\
\text { ATCC } \\
9945 \mathrm{a}\end{array}$ & 98.58 & 437 & 424 \\
\hline
\end{tabular}


Table 2 (continued)

\begin{tabular}{|c|c|c|c|c|c|c|c|c|}
\hline \multirow[t]{2}{*}{ Enzymes } & \multirow{2}{*}{$\begin{array}{l}\text { Accession } \\
\text { number }\end{array}$} & \multirow[t]{2}{*}{ Activity } & \multirow{2}{*}{$\begin{array}{l}\text { CAZyme } \\
\text { family }\end{array}$} & \multicolumn{2}{|c|}{ Reference genes } & \multirow[t]{2}{*}{ Identity (\%) } & \multirow{2}{*}{$\begin{array}{l}\text { Subject } \\
\text { sequence } \\
\text { length (bp) }\end{array}$} & \multirow{2}{*}{$\begin{array}{l}\text { Alignment } \\
\text { length (bp) }\end{array}$} \\
\hline & & & & $\begin{array}{l}\text { Accession } \\
\text { number }\end{array}$ & Species & & & \\
\hline & $\begin{array}{l}\text { EOOON- } \\
\text { OAK_02113 }\end{array}$ & Levansucrase & GH68 & ARA87315.1 & $\begin{array}{l}\text { Bacillus par- } \\
\text { alicheni- } \\
\text { formis } \\
\text { MDJK30 }\end{array}$ & 100 & 481 & 481 \\
\hline & $\begin{array}{l}\text { EOOON- } \\
\text { OAK_04229 }\end{array}$ & Hypothetical protein & GH73 & QEO06161.1 & $\begin{array}{l}\text { Bacillus par- } \\
\text { alicheni- } \\
\text { formis } \\
\text { A4-3 }\end{array}$ & 98.95 & 570 & 570 \\
\hline & $\begin{array}{l}\text { EOOON- } \\
\text { OAK_03432 }\end{array}$ & $\begin{array}{l}\text { Reducing-end xylose- } \\
\text { releasing exo-oli- } \\
\text { goxylanase Rex8A } \\
\text { xylanase probable }\end{array}$ & GH8 & QFY39429.1 & $\begin{array}{l}\text { Bacillus par- } \\
\text { alicheni- } \\
\text { formis } \text { FA6 }\end{array}$ & 99.77 & 434 & 434 \\
\hline \multirow[t]{4}{*}{$\begin{array}{l}\text { Cellulose- } \\
\text { related }\end{array}$} & $\begin{array}{l}\text { EOOON- } \\
\text { OAK_03622 }\end{array}$ & Endoglucanase S & GH12 & ARA86997.1 & $\begin{array}{l}\text { Bacillus par- } \\
\text { alicheni- } \\
\text { formis } \\
\text { MDJK30 }\end{array}$ & 100 & 261 & 261 \\
\hline & $\begin{array}{l}\text { EOOON- } \\
\text { OAK_01156 }\end{array}$ & Exoglucanase-2 & GH48 & AJO18128.1 & $\begin{array}{l}\text { Bacillus par- } \\
\text { alicheni- } \\
\text { formis } \\
\text { BL-09 }\end{array}$ & 100 & 717 & 704 \\
\hline & $\begin{array}{l}\text { EOOON- } \\
\text { OAK_01385 }\end{array}$ & Endoglucanase & GH5, CBM3 & AJO18373.1 & $\begin{array}{l}\text { Bacillus par- } \\
\text { alicheni- } \\
\text { formis } \\
\text { BL-09 }\end{array}$ & 99.81 & 518 & 518 \\
\hline & $\begin{array}{l}\text { EOOON- } \\
\text { OAK_01155 }\end{array}$ & Endoglucanase A & GH9CBM3 & AJO18127.1 & $\begin{array}{l}\text { Bacillus par- } \\
\text { alicheni- } \\
\text { formis } \\
\text { BL-09 }\end{array}$ & 100 & 653 & 653 \\
\hline \multirow[t]{3}{*}{$\begin{array}{l}\text { Glucose } \\
\text { metabo- } \\
\text { lism }\end{array}$} & $\begin{array}{l}\text { EOOON- } \\
\text { OAK_00372 }\end{array}$ & $\begin{array}{l}\text { 6-Phospho-beta-glu- } \\
\text { cosidase GmuD }\end{array}$ & GH1 & AJO18923.1 & $\begin{array}{l}\text { Bacillus par- } \\
\text { alicheni- } \\
\text { formis } \\
\text { BL-09 }\end{array}$ & 100 & 471 & 471 \\
\hline & $\begin{array}{l}\text { EOOON- } \\
\text { OAK_01723 }\end{array}$ & $\begin{array}{l}\text { 6-Phospho-beta-glu- } \\
\text { cosidase GmuD }\end{array}$ & GH1 & AJO20590.1 & $\begin{array}{l}\text { Bacillus par- } \\
\text { alicheni- } \\
\text { formis } \\
\text { BL-09 }\end{array}$ & 99.16 & 478 & 478 \\
\hline & $\begin{array}{l}\text { EOOON- } \\
\text { OAK_03054 }\end{array}$ & $\begin{array}{l}\text { Putative 6-phos- } \\
\text { pho-beta-glucosi- } \\
\text { dase }\end{array}$ & GH4 & $\begin{array}{l}\text { ARA84298.1 } \\
0\end{array}$ & $\begin{array}{l}\text { Bacillus par- } \\
\text { alicheni- } \\
\text { formis } \\
\text { MDJK30 }\end{array}$ & 99.55 & 444 & 444 \\
\hline \multirow[t]{2}{*}{$\begin{array}{l}\text { Hemicel- } \\
\text { lulose or } \\
\text { cellulose } \\
\text { related }\end{array}$} & $\begin{array}{l}\text { EOOON- } \\
\text { OAK_01655 }\end{array}$ & $\begin{array}{l}\text { Putative 6-phos- } \\
\text { pho-beta-glucosi- } \\
\text { dase }\end{array}$ & GH4 & ARA87677.1 & $\begin{array}{l}\text { Bacillus par- } \\
\text { alicheni- } \\
\text { formis } \\
\text { MDJK30 }\end{array}$ & 100 & 442 & 442 \\
\hline & $\begin{array}{l}\text { EOOON- } \\
\text { OAK_01158 }\end{array}$ & Hypothetical protein & GH5 & QEO07050.1 & $\begin{array}{l}\text { Bacillus par- } \\
\text { alicheni- } \\
\text { formis } \\
\text { A4-3 }\end{array}$ & 100 & 395 & 395 \\
\hline \multirow[t]{2}{*}{$\begin{array}{l}\text { Pectin degra- } \\
\text { dation }\end{array}$} & $\begin{array}{l}\text { EOOON- } \\
\text { OAK_04163 }\end{array}$ & $\begin{array}{l}\text { Unsaturated rham- } \\
\text { nogalacturonyl } \\
\text { hydrolase YesR }\end{array}$ & GH105 & AJO17709.1 & $\begin{array}{l}\text { Bacillus par- } \\
\text { alicheni- } \\
\text { formis } \\
\text { BL-09 }\end{array}$ & 99.71 & 344 & 344 \\
\hline & $\begin{array}{l}\text { EOOON- } \\
\text { OAK_02457 }\end{array}$ & $\begin{array}{l}\text { Unsaturated rham- } \\
\text { nogalacturonyl } \\
\text { hydrolase YteR }\end{array}$ & GH105 & AJO19596.1 & $\begin{array}{l}\text { Bacillus par- } \\
\text { alicheni- } \\
\text { formis } \\
\text { BL-09 }\end{array}$ & 99.73 & 373 & 373 \\
\hline
\end{tabular}


Table 2 (continued)

\begin{tabular}{|c|c|c|c|c|c|c|c|c|}
\hline \multirow[t]{2}{*}{ Enzymes } & \multirow{2}{*}{$\begin{array}{l}\text { Accession } \\
\text { number }\end{array}$} & \multirow[t]{2}{*}{ Activity } & \multirow{2}{*}{$\begin{array}{l}\text { CAZyme } \\
\text { family }\end{array}$} & \multicolumn{2}{|c|}{ Reference genes } & \multirow[t]{2}{*}{ Identity (\%) } & \multirow{2}{*}{$\begin{array}{l}\text { Subject } \\
\text { sequence } \\
\text { length (bp) }\end{array}$} & \multirow{2}{*}{$\begin{array}{l}\text { Alignment } \\
\text { length (bp) }\end{array}$} \\
\hline & & & & $\begin{array}{l}\text { Accession } \\
\text { number }\end{array}$ & Species & & & \\
\hline & $\begin{array}{l}\text { EOOON- } \\
\text { OAK_02256 }\end{array}$ & $\begin{array}{l}\text { Exo-poly-alpha-D-ga- } \\
\text { lacturonosidase }\end{array}$ & $\mathrm{GH} 28$ & QFY37288.1 & $\begin{array}{l}\text { Bacillus par- } \\
\text { alicheni- } \\
\text { formis FA6 }\end{array}$ & 100 & 436 & 434 \\
\hline & $\begin{array}{l}\text { EOOON- } \\
\text { OAK_02563 }\end{array}$ & Hypothetical protein & PL1 & QFY37765.1 & $\begin{array}{l}\text { Bacillus par- } \\
\text { alicheni- } \\
\text { formis FA6 }\end{array}$ & 100 & 494 & 494 \\
\hline & $\begin{array}{l}\text { EOOON- } \\
\text { OAK_04252 }\end{array}$ & Pectate lyase & PL1 & AJO17744.1 & $\begin{array}{l}\text { Bacillus par- } \\
\text { alicheni- } \\
\text { formis } \\
\text { BL-09 }\end{array}$ & 99.53 & 428 & 428 \\
\hline & $\begin{array}{l}\text { EOOON- } \\
\text { OAK_01685 }\end{array}$ & $\begin{array}{l}\text { Pectate trisaccharide- } \\
\text { lyase }\end{array}$ & PL1 & QEO04986.1] & $\begin{array}{l}\text { Bacillus par- } \\
\text { alicheni- } \\
\text { formis } \\
\text { A4-3 }\end{array}$ & 99.71 & 341 & 341 \\
\hline & $\begin{array}{l}\text { EOOON- } \\
\text { OAK_04170 }\end{array}$ & $\begin{array}{l}\text { Rhamnogalacturonan } \\
\text { exolyase YesX }\end{array}$ & PL11 & QEO06607.1 & $\begin{array}{l}\text { Bacillus par- } \\
\text { alicheni- } \\
\text { formis } \\
\text { A4-3 }\end{array}$ & 100 & 628 & 628 \\
\hline & $\begin{array}{l}\text { EOOON- } \\
\text { OAK_04168 }\end{array}$ & $\begin{array}{l}\text { Rhamnogalacturonan } \\
\text { endolyase YesW }\end{array}$ & PL11 & QEO08401.1 & $\begin{array}{l}\text { Bacillus par- } \\
\text { alicheni- } \\
\text { formis } \\
\text { A4-3 }\end{array}$ & 100 & 622 & 622 \\
\hline & $\begin{array}{l}\text { EOOON- } \\
\text { OAK_04174 }\end{array}$ & Hypothetical protein & PL26 & QEO06610.1 & $\begin{array}{l}\text { Bacillus par- } \\
\text { alicheni- } \\
\text { formis } \\
\text { A4-3 }\end{array}$ & 99.07 & 886 & 863 \\
\hline & $\begin{array}{l}\text { EOOON- } \\
\text { OAK_02080 }\end{array}$ & Pectate lyase $\mathrm{C}$ & PL3 & ARA87346.1 & $\begin{array}{l}\text { Bacillus par- } \\
\text { alicheni- } \\
\text { formis } \\
\text { MDJK30 }\end{array}$ & 99.55 & 222 & 221 \\
\hline & $\begin{array}{l}\text { EOOON- } \\
\text { OAK_01392 }\end{array}$ & Hypothetical protein & PL9 & QEO07258.1 & $\begin{array}{l}\text { Bacillus par- } \\
\text { alicheni- } \\
\text { formis } \\
\text { A4-3 }\end{array}$ & 100 & 468 & 468 \\
\hline
\end{tabular}

The accession numbers correspond to the CDS sequences annotated with Prokka as indicated in the manuscript. The corresponding sequences are provided in Figure S2

licheniformis that has been widely used in the fermentation industry for production of enzymes, antibiotics and other chemicals (Madslien et al. 2012).

Hereafter, we focused on CCMM B940 glycoside hydrolases related to hemicellulose, cellulose and pectin degradation, comparing their protein sequences to the sequences of $\mathrm{GH}$ and pectate lyase (PL) of seven strains of B. paralicheniformis (A4-3, ATCC 9945a, BL-09, CBMAI 1303, FA6, MDJK30, ZAP17) available in the CAZY database (Lombard et al. 2014; database release 22 November 2020). Blast results was obtained using default parameters. Best hits with almost $90 \%$ amino-acid identity and 50\% length alignment were selected and illustrated in Table 2 (the corresponding sequences are provided in Fig S2). Among 74 GH and PL sequences from CCMM B940 showed homology to other strains of $B$. paralicheniformis, 52 are dedicated to the degradation of carbohydrates in plant cell walls, representing 27 different CAZymes families according to the classification of B. Henrissat (Lombard et al. 2014). Thirty-two sequences of GH1, GH3, GH5, GH8, GH11, GH16, GH26, GH30, GH31, GH32, GH42, GH43, GH51, GH53, GH68, GH73 were linked to the degradation of hemicellulose, 4 sequences of GH5, GH9, GH12, GH48 for cellulose metabolism, 1 sequence (GH5) either for hemicellulose or cellulose degradation, and 11 sequences of $\mathrm{GH}$ (GH28, GH105) and PL (PL1, PL3, PL9, PL11, PL2) were attributed to pectin degradation (Table 2). Four sequences corresponded to enzymes (GH1, GH4) involved in glycolytic pathways. The remaining sequences were mainly related to the hydrolysis of starch and peptidoglycan (not shown). 
These predictions first confirmed the experimental observations in this study for the degradation of xylan, lichenan and CMC as the CCMM B940 genome carries glycoside hydrolases from GH5, GH9, GH11 and GH16 families of CAZYmes known to target these substrates. They also provided additional information on the carbohydrate metabolism of CCMM B940 such as pectinase activity as well as the presence of carbohydrate-binding modules (CBM3, CBM6, CBM66) associated with GHs helping them to bind to cellulose or hemicellulose polysaccharides to improve their efficiency. A few other studies (Wang et al. 2017; Chen et al. 2018) examined the genomic sequences of $B$. paralicheniformis and predicted their CAZymes, but without the experimental validation. To our knowledge, this is the first report that combines in silico genomic analysis and in vitro experiments to study the carbohydrate metabolism of $B$. paralicheniformis. These combined analyses reinforce the practical and potential use of CCMM B940 strain for industrial purposes. Indeed, Bacillus species are known to produce $60 \%$ of commercially available enzymes, mostly being homologous proteins that are naturally secreted in the growth medium (Westers et al. 2004). The strain CCMM B940 exhibits cellulolytic and hemicellulolytic activities at high temperature and produces extracellular thermostable enzymes.

Based on whole-genome sequencing, we demonstrated that the B. aerius strain CCMM B940 could be reclassified as $B$. paralicheniformis. Genomic analysis confirmed the fibrolytic potential of the strain CCMM B940 observed in vitro using purified and natural substrates and provided information on its ability to degrade pectins. This statement reinforces the strain's interest especially in agro-waste bioconversion. To our knowledge, this is the first report of lichenase and xylanase activities by a thermophilic strain of B. paralicheniformis isolated from a hot spring. The CCMM B940 strain is part of the large Coordinated Moroccan Collections of Microorganisms (CCMM), which comprise more than 1800 isolates of bacteria, yeasts and fungi. Many of these microorganisms have also been isolated from extremophile environments (Berrada et al. 2012; Aanniz et al. 2015) and they may harbor beneficial attributes such as production of heat-resistance enzymes as already observed in B. amyloliquefaciens (Beladjal et al. 2018) and B. subtilis (den Besten et al. 2017) strains. For this purpose, complete genome sequencing not only enables accurate identification and reclassification of CCMM isolates, i.e. the thermophilic strains of the $B$. aerius group, but also opens the door to the field of biotechnological applications such as production of second- and third-generation biofuels from raw or pretreated biomass, medical and nutraceutical fields and food processing (Benedetti et al. 2019), in the favor of the fibrolytic potential (CAZymes) of these strains. Enzymatic activities of these strains should be further studied to determine the most suitable markets in biotechnology (agro-waste bioconversion, depollution, health, pharmaceuticals, etc....).

\section{Accession numbers}

The assembled genome and all relevant sequences were deposited in NCBI's GenBank on November 24, 2020 under the following accession numbers, BioProject PRJNA680612; BioSample SAMN16895636; Genome JADRJL000000000.

Supplementary Information The online version contains supplementary material available at https://doi.org/10.1007/s13205-021-02919-0.

Acknowledgements Funding for this research was provided by Belgian Cooperation FRAB/CCMM2, the National Center for Scientific and Technical Research (CNRST) and the National Research Institute for Agriculture, Food and Environment (INRAE). Maski Soufiane is a PhD student at Faculty of Science, Mohammed V University, Rabat, Morocco. Serigne Inssa Ngom is a recipient of a grant for doctoral research allocated by the French ministry of higher education and research (doctoral school 569, University of Paris-Saclay). The authors would like to thank Mrs Zehra Esra Ilhan for English improvement of the manuscript.

Author contributions MA, EE, MB and CBM conceived the study. SM, SIN, MA, EE, CBM designed the experiments. SM, SIN did genomic and enzymatic analyses, respectively. SIN, BR, TC prepared the samples and extracted DNA. SM performed nucleic Blast, the assembly and the annotation of the genome, and performed the map of functional categories. SIN performed all the enzymatic assays. MA, EE, MB, BR, CBM analyzed the data. SM, SIN, CBM, MA wrote the manuscript with the help of all authors. All authors have read and approved the final manuscript.

\section{Declarations}

Conflict of interest The authors declare that they have no conflict of interest in the publication.

Open Access This article is licensed under a Creative Commons Attribution 4.0 International License, which permits use, sharing, adaptation, distribution and reproduction in any medium or format, as long as you give appropriate credit to the original author(s) and the source, provide a link to the Creative Commons licence, and indicate if changes were made. The images or other third party material in this article are included in the article's Creative Commons licence, unless indicated otherwise in a credit line to the material. If material is not included in the article's Creative Commons licence and your intended use is not permitted by statutory regulation or exceeds the permitted use, you will need to obtain permission directly from the copyright holder. To view a copy of this licence, visit http://creativecommons.org/licenses/by/4.0/.

\section{References}

Aanniz T, Ouadghiri M, Melloul M, Swings J, Elfahime E, Ibijbijen J, Ismaili M, Amar M (2015) Thermophilic bacteria in Moroccan hot springs, salt marshes and desert soils. Braz J Microbiol 46(2):443-453. https://doi.org/10.1590/s1517-838246220140219 
Bankevich A, Nurk S, Antipov D et al (2012) SPAdes: a new genome assembly algorithm and its applications to single-cell sequencing. J Comput Biol 19(5):455-477. https://doi.org/10.1089/cmb. 2012.0021h

Beladjal L, Gheysens T, Clegg JS, Amar M, Mertens J (2018) Life from the ashes: survival of dry bacterial spores after very high temperature exposure. Extremophiles 22(5):751-759. https://doi. org/10.1007/s00792-018-1035-6

Benedetti M, Locci F, Gramegna G, Sestili F, Savatin DV (2019) Green production and biotechnological applications of cellwall lytic enzymes. Appl Sci 9(23):5012. https://doi.org/10.3390/app92 35012

Berrada I, Willems A, de Vos P, El Fahime E, Swings J, Bendaou N, Melloul M, Amar M (2012) Diversity of culturablemoderately halophilic and halotolerant bacteria in a marsh and two salterns a protected ecosystem of lower Loukkos (Morocco). Afr J Microbiol Res 6(10):2419-2434. https://doi.org/10.5897/AJMR11.1490

Biely P, Singh S, Puchart V (2016) Towards enzymatic breakdown of complex plant xylan structures: state of the art. Biotechnol Adv 34(7):1260-1274. https://doi.org/10.1016/j.biotechadv.2016.09. 001

Bolger AM, Lohse M, Usadel B (2014) Trimmomatic: a flexible trimmer for illumina sequence data. Bioinformatics 30(15):21142120. https://doi.org/10.1093/bioinformatics/btu 170

Bouchaou L, Warner NR, Tagma T, Hssaisoune M, Vengosh A (2017) The origin of geothermal waters in morocco: multiple isotope tracers for delineating sources of water-rock interactions. Appl Geochem 84:244-253. https://doi.org/10.1016/j.apgeochem.2017. 07.004

Bradford MM (1976) A rapid and sensitive method for the quantitation of microgram quantities of protein utilizing the principle of protein-dye binding. Anal Biochem 72(1-2):248-254. https://doi. org/10.1006/abio.1976.9999

Chaumeil PA, Mussig AJ, Hugenholtz P, Parks DH (2020) GTDB-Tk: a toolkit to classify genomes with the genome taxonomy database. Bioinformatics 36(6):1925-1927. https://doi.org/10.1093/ bioinformatics/btz848

Chen L, Gu W, Xu HY et al (2018) Comparative genome analysis of Bacillus velezensis reveals a potential for degrading lignocellulosic biomass. 3 Biotech 8(5):253. https://doi.org/10.1007/ s13205-018-1270-7

Chun BH, Kim KH, Jeong SE, Jeon CO (2019) Genomic and metabolic features of the bacillus amyloliquefaciens group- $\mathrm{B}$. Amyloliquefaciens, B. Velezensis, and B. Siamensis-revealed by pan-genome analysis. Food Microbiol 77:146-157. https://doi. org/10.1016/j.fm.2018.09.001

Cidu R, Bahaj S (2000) Geochemistry of thermal waters from Morocco. Geothermics 29(3):407-430. https://doi.org/10.1016/ S0375-6505(00)00007-9

Datta S, Saha D, Chattopadhyay L, Majumdar B (2020) Genome comparison identifies different bacillus species in a bast fibreretting bacterial consortium and provides insights into pectin degrading genes. Sci Rep 10(1):1-15. https://doi.org/10.1038/ s41598-020-65228-1

de la Torre I, Martin-Dominguez V, Acedos MG, Esteban J, Santos VE, Ladero M (2019) Utilisation/upgrading of orange peel waste from a biological biorefinery perspective. Appl Microbiol Biotechnol 103(15):5975-5991. https://doi.org/10.1007/s00253-019-09929-2

den Besten HMW, Berendsen EM, Wells-Bennik MHJ, Straatsma H, Zwietering MH (2017) Two complementary approaches to quantify variability in heat resistance of spores of Bacillus subtilis. Int J Food Microbiol 253:48-53. https://doi.org/10.1016/j.ijfoo dmicro.2017.04.014

Dhillon GS, Kaur S, Brar SK (2013) Perspective of apple processing 401 wastes as low-cost substrates for bioproduction of high value products: a review. Renewable 402 and sustainable energy reviews. Pergamon. https://doi.org/10.1016/j.rser.2013.06.046

Du Y, Ma J, Yin Z et al (2019) Comparative genomic analysis of Bacillus paralicheniformis MDJK30 with its closely related species reveals an evolutionary relationship between $B$. paralicheniformis and B. licheniformis. BMC Genom 20(1):283. https://doi.org/10. 1186/s12864-019-5646-9h

Dunlap CA (2015) The status of the species Bacillus aerius. Request for an opinion. Int J Syst Evol Microbiol 65(7):2341. https://doi. org/10.1099/ijs.0.000271t

Fan B, Blom J, Klenk H-P, Borriss R (2017) Bacillus amyloliquefaciens, Bacillus velezensis, and Bacillus siamensis form an 'Operational Group B. amyloliquefaciens' within the B. subtilis species Complex. Front Microbiol 8:22. https://doi.org/10.3389/fmicb. 2017.00022t

Gong G, Kim S, Lee SM, Woo HM, Park TH, Um Y (2017) Complete genome sequence of Bacillus sp. 275, producing extracellular cellulolytic, xylanolytic and ligninolytic enzymes. J Biotechnol 254:59-62. https://doi.org/10.1016/j.jbiotec.2017.05.021

Gurevich A, Saveliev V, Vyahhi N, Tesler G (2013) QUAST: quality assessment tool for genome assemblies. Bioinformatics 29(8):1072-1075. https://doi.org/10.1093/bioinformatics/btt086

Houfani AA, Anders N, Spiess AC, Baldrian P, Benallaoua S (2020) Insights from enzymatic degradation of cellulose and hemicellulose to fermentable sugars: a review. Biomass Bioenergy 134:105481. https://doi.org/10.1016/j.biombioe.2020.105481

Huerta-Cepas J, Forslund K, Coelho LP, Szklarczyk D, Jensen LJ, von Mering C, Bork P (2017) Fast genome-wide functional annotation through orthology assignment by EggNOG-mapper. Mol Biol Evol 34(8):2115-2122. https://doi.org/10.1093/molbev/msx148

Jain C, Rodriguez RLm, Phillippy AM, Konstantinidis KT, Aluru S (2018) High-throughput ANI analysis of $90 \mathrm{~K}$ prokaryotic genomes reveals clear species boundaries. Nat Commun 9:5114. https://doi.org/10.1038/s41467-018-07641-9

Joglekar SN, Pathak PD, Mandavgane SA, Kulkarni BD (2019) Process of fruit peel waste biorefinery: a case study of citrus waste biorefinery, its environmental impacts and recommendations. Environ Sci Pollut Res 26(34):34713-34722. https://doi.org/10. 1007/s11356-019-04196-0

Kazeem MO, Shah UKM, Baharuddin AS, AbdulRahman NA (2017) Prospecting agro-waste cocktail: supplementation for cellulase production by a newly isolated thermophilic B. licheniformis 2D55. Appl Biochem Biotechnol 182(4):1318-1340. https://doi. org/10.1007/s12010-017-2401-z

Knapik K, Becerra M, González-Siso MI (2019) Microbial diversity analysis and screening for novel xylanase enzymes from the sediment of the lobios hot spring in Spain. Sci Rep 9(1):11195. https:// doi.org/10.1038/s41598-019-47637-z

Langmead B, Salzberg SL (2012) Fast gapped-read alignment with bowtie 2. Nat Methods 9(4):357-359

Lombard V, Golaconda Ramulu H, Drula E, Coutinho PM, Henrissat B (2014) The carbohydrate-active enzymes database (CAZy) in 2013. Nucleic Acids Res 42(Database issue):D490-D495. https:// doi.org/10.1093/nar/gkt1178

Madslien EH, Olsen JS, Granum PE, Blatny JM (2012) Genotyping of $B$. licheniformis based on a novel multi-locus sequence typing (MLST) scheme. BMC Microbiol 12(1):230. https://doi.org/10. 1186/1471-2180-12-230

Miller GL (1959) Use of dinitrosalicylic acid reagent for determination of reducing sugar. Anal Chem 31:426-428. https://doi.org/ 10.1021/ac60147a030

Othoum G, Prigent S, Derouiche A et al (2019) Comparative genomics study reveals Red Sea Bacillus with characteristics associated with potential microbial cell factories (MCFs). Sci Rep 9(1):2395524900. https://doi.org/10.1038/s41598-019-55726-2 
Parab P, Khandeparker R, Amberkar U, Khodse V (2017) Enzymatic saccharification of seaweeds into fermentable sugars by xylanase from marine Bacillus sp. strain BT21. 3 Biotech 7(5):296. https:// doi.org/10.1007/s13205-017-0921-4

Parks DH, Imelfort M, Skennerton CT, Hugenholtz P, Tyson GW (2015) CheckM: assessing the quality of microbial genomes recovered from isolates, single cells, and metagenomes. Genome Res 25(7):1043-1055. https://doi.org/10.1101/gr.186072.114

Patrascu O, Beguet-Crespel F, Marinelli L, le Chatelier E, Abraham A-L, Leclerc M, Klopp C, Terrapon N, Henrissat B, Blottiere HM, Dore J, Bera-Maillet C (2017) A fibrolytic potential in the human ileum mucosal microbiota revealed by functional metagenomic. Sci Rep 7:40248. https://doi.org/10.1038/srep40248

Rey MW, Ramaiya P, Nelson BA et al (2004) Complete genome sequence of the industrial bacterium Bacillus licheniformis and comparisons with closely related Bacillus species. Genome Biol 5(10):R77. https://doi.org/10.1186/gb-2004-5-10-r77

Rivas B, Torrado A, Torre P, Converti A, Dominguez JM (2008) Submerged citric acid fermentation on orange peel autohydrolysate. J Agric Food Chem 56(7):2380-2387. https://doi.org/10.1021/ jf073388r

Seemann T (2014) Prokka: rapid prokaryotic genome annotation. Bioinformatics 30(14):2068-2069. https://doi.org/10.1093/bioin formatics/btu 153
Thapa S, Mishra J, Arora N et al (2020) Microbial cellulolytic enzymes: diversity and biotechnology with reference to lignocellulosic biomass degradation. Rev Environ Sci Biotechnol 19(3):621-648. https://doi.org/10.1007/s11157-020-09536-y

Wang Y, Liu H, Liu K et al (2017) Complete genome sequence of Bacillus paralicheniformis MDJK30, a plant growthpromoting rhizobacterium with antifungal activity. Genome Announc 5(25):577-594. https://doi.org/10.1128/genomeA.00577-17

Westers L, Westers H, Quax WJ (2004) Bacillus subtilis as cell factory for pharmaceutical proteins: a biotechnological approach to optimize the host organism. Biochimica Et Biophysica Acta (molecular Cell Research) 1694(1-3 SPEC.ISS.):299-310. https:// doi.org/10.1016/j.bbamcr.2004.02.011

Zeng Y, Himmel ME, Ding SY (2017) Visualizing chemical functionality in plant cell walls mike himmel. Biotechnol Biofuels 10(1):263. https://doi.org/10.1186/s13068-017-0953-3

Zhang Z-Y, Raza MF, Zheng Z et al (2018) Complete genome sequence of Bacillus velezensis ZY-11 reveals the genetic basis for its hemicellulosic/cellulosic substrate-inducible xylanase and cellulase activities. 3 Biotech 8(11):465. https://doi.org/10.1007/ s13205-018-1490-x 